\title{
Spiritual Needs of Patients with Chronic Pain Diseases and Cancer - Validation of the Spiritual NeEds Questionnaire
}

\author{
A. Büssing ${ }^{1}$, H.-J. Balzat ${ }^{2}$, P. Heusser ${ }^{1,3}$ \\ ${ }^{1}$ Center for Integrative Medicine, University of Witten/Herdecke, Germany; \\ ${ }^{2}$ Pain Outpatient Clinic, Community Hospital Herdecke, Germany; \\ ${ }^{3}$ Institute for Complementary Medicine (KIKOM), University of Bern, Switzerland
}

\begin{abstract}
Purpose: For many patients confronted with chronic diseases, spirituality/religiosity is a relevant resource to cope. While most studies on patients' spiritual needs refer to the care of patients at the end of life, our intention was to develop an instrument to measure spiritual, existential and psychosocial need of patients with chronic diseases.

Methods: In an anonymous cross-sectional survey, we applied the Spiritual Needs Questionnaire (SpNQ version 1.2.) to 210 patients ( $75 \%$ women, mean age $54 \pm$ 12 years) with chronic pain conditions $(67 \%)$, cancer $(28 \%)$, other chronic conditions (5\%). Patients were recruited at the Community Hospital Herdecke, the Institute for Complementary Medicine (University of Bern), and at a conference of a cancer support group in Herten.

Results: Factor analysis of the 19-item instrument (Cronbach's alpha $=.93$ ) pointed to 4 factors which explain 67\% of variance: Religious Needs, Need for Inner Peace, Existentialistic Needs (Reflection / Meaning), and Actively Giving. Within the main sample of patients with chronic pain and cancer, Needs for Inner Peace had the highest scores, followed by Self competent Attention; Existentialistic Needs had low scores, while the Religious Needs scores indicate no interest. Patients with cancer had significantly higher SpNQ scores than patients with chronic pain conditions. There were just some weak associations between $A c$ tively Giving and life satisfaction $(\mathrm{r}=.17 ; \mathrm{p}=.012)$, and negatively with the symptom score $(\mathrm{r}=-.29 ; \mathrm{p}<$ .0001); Need for Inner Peace was weakly associated with satisfaction with treatment efficacy $(r=.24$; $p<$ .0001). Regression analyses reveal that the underlying disease (i.e., cancer) was of outstanding relevance for the patients' spiritual needs.

Conclusion: The preliminary results indicate that spiritual needs are conceptually different from life satisfaction, and can be interpreted as the patients' longing for spiritual well-being. Methods how health care professionals may meet their patients' spiritual needs remain to be explored.
\end{abstract}

Key words: Spiritual needs, chronic diseases, spirituality, questionnaire, validation

\section{INTRODUCTION}

Both chronic illness and life threatening diseases confront patients with the question of meaning and purpose in life. In such times of need, several patients rely on external resources of help, i.e. medical doctors, alternative information and help, but also God's help [1]. Studies have shown that spirituality/religiosity can be a source to rely on [2]. An increasing number of published studies have examined the connection between spirituality/religiosity, health and quality of life, and its potential to prevent, heal or cope with disease [3-14]. Most of these studies state that religious involvement is related to better mental and physical health, improved coping with illness, and improved medical outcomes. However, several reviews state methodological problems, and thus firm conclusions can not easily be drawn [7, 12]; moreover, a recent systematic review confirmed that spirituality/religiosity was associated with reduced mortality only in healthy population studies, but not in diseased population studies [11].

Whatever the scientific evidence may prove, one can not ignore that spirituality/religiosity is a relevant resource to cope for many patients [1, 12-17]. Particularly in cancer patients, spirituality/religiosity may be beneficial maintaining self-esteem, providing a sense of meaning and purpose, giving emotional comfort and providing a sense of hope [12]. In a recent study among advanced cancer patients, most $(88 \%)$ considered religion to be at least somewhat important, and a majority $(72 \%)$ reported that their spiritual needs were supported minimally or not at all by the medical system [19]. This is of importance, particularly because spiritual support was associated with better quality of life [19].

However, most studies on patients' spiritual needs refer to the care of patients at the end of life [20, 21, 23$25,27,28]$, and are often qualitative results or surveys, while there is a lack of conceptualisations to measure spiritual, existential and psychosocial need of patients with putatively long courses of chronic illness such as chronic pain conditions, cancer, HIV infection etc.

A qualitative study by Grant et al. found that patients' spiritual needs addressed the loss of roles and self-identity and fear of dying; several patients sought 
to make sense of life in relation to transcendence [29]. Is was not too surprising that these needs were related to anxiety, sleeplessness, and despair [29]. Murray interviewed terminally-ill patients with inoperable lung cancer and heart failure which expressed needs for love, meaning, purpose and sometimes transcendence [20]. A qualitative study among 13 French patients at the end of life defined the following needs: reinterpretation of life, search for meaning, densification of the connection to the world, to loved ones and to oneself, control, vital energy, ambivalence to the future, confrontation with death, relationship to transcendence [27]. In older Taiwanese patients with terminal cancer two constitutive patterns, "caring for the mortal body" and "transcending the worldly being" emerged from the interviews [26]. Also a meta-summary of the qualitative literature on spiritual perspectives of adults extracted thematic pattern of spirituality at the end of life, which were spiritual despair (alienation, loss of self, dissonance), spiritual work (forgiveness, selfexploration, search for balance), and spiritual well-being (connection, selfactualization, consonance) [30]. Moadel et al. investigated spiritual/existential needs of cancer patients from the USA, and found that patients wanted help with overcoming fears $(51 \%)$, finding hope $(42 \%)$, finding meaning in life $(40 \%)$, finding spiritual resources $(39 \%)$, or someone to talk to about finding peace of mind (43\%), meaning of life $(28 \%)$, and dying and death (25\%) [31]. Hermann measured the spiritual needs of patients near the end of life enrolling hospice patients [21] and found that several patients reported a higher number of unmet spiritual needs [22]. Enrolling cancer patients in hospice home care, it became evident a that spiritual needs may exhibit a great variability; among these needs, family was the most frequently cited one $(80 \%)$; attending religious services was the most frequently cited unmet need [25]. In Korean patients with cancer, Yong et al. identified 5 sub-constructs of spiritual needs [32], i.e., love and connection, hope and peace, meaning and purpose, relationship with God, and acceptance of dying.

Our intention was to develop an instrument addressing the spiritual needs of patients with chronic diseases, and to account for the fact that secularisation and individualisation proceed particularly in Europe. Consequently, the conceptualization of patients' spiritual needs has to involve a much more open concept of spirituality which is valid for more secular countries, too, as described [33]. Because these needs have to be seen in the context of subjective well-being and quality of life, addressing these needs is of outstanding importance for health care and health care research. Therefore, we aimed to validate a newly developed instrument, the Spiritual Needs Questionnaire (SpNQ) to measure spiritual, existential and psychosocial needs, and to analyse the self-ascribed importance of the respective dimensions.

\section{Materials AND Methods}

\section{PATIENTS}

For this cross-sectional anonymous survey, we recruited a convenience sample of 210 patients from the
Pain Outpatient Clinic, Community Hospital Herdecke (Germany), the Institute for Complementary Medicine (KIKOM) of the University of Bern (Switzerland), and from a conference of a cancer support group in Herten (Germany). The ethical committees of the University Witten/Herdecke (\#74/2008) and the Canton of Bern, respectively, approved to conduct the anonymous survey.

All patients were informed of the purpose of the investigation, were assured of confidentiality, gave informed consent to participate, and completed the German language questionnaire by themselves which neither asked for names, initials, addresses or clinical details (with the exception of a diagnosis).

\section{Measures}

The items of the Spiritual Needs Questionnaire (SpRQ) were developed with respect to results of our previous research on spiritual/religious attitudes and convictions and frequency of engagement in distinct forms of a spiritual practice among patients with various chronic diseases [1, 12-14, 17, 34-36], and current expressions of spirituality among health and sick individuals [33].

On the basis of these results, we had a 24-item construct which addresses both private and institutional religiosity (i.e., praying, congregational activities, reading spiritual/ religious books, involvement of chaplains etc.); forgiveness; existentialistic issues in terms of life reflection and meaning of life and suffering; social interactions, attention by others, and active compassionate turning to others; need for inner peace and beauty of nature. All items were scored with respect to the self ascribed importance on a 4-point scale from disagreement to agreement ( 0 - not at all; 1 - somewhat; 2 - very; 3 - extremely).

To make statements about the conceptual relationships between spiritual needs and life satisfaction (i.e., one may assume that low life satisfaction might be associated with higher needs and vice versa), we used the Brief Multidimensional Life Satisfaction Scale (BMLSS) [37]. The eight items of the scale refer to intrinsic dimensions (Myself, Overall Life), social dimensions (Friendships, Family life), external dimension (Work, Where I live), and the prospective dimension (Financial Situation, Future Prospects). The items were scored on a 7-point scale from dissatisfaction to satisfaction $(0$ Terrible; 1 - Unhappy; 2 - Mostly dissatisfied; 3 - Mixed (about equally satisfied and dissatisfied); 4 - Mostly satisfied; 5 - Pleased; 6 - Delighted). The sum score was referred to a $100 \%$ level ("Delighted").

Moreover, we used two additional items to address patient satisfaction (i.e., health situation and effectiveness of treatment), which were also scored on a 7 point scale from dissatisfaction to satisfaction.

To asses the intensity of symptoms ascribed by the patients, we used a visual analogue scale (VAS) ranging from 0 (none) to 100 (worst, unbearable).

\section{STATISTICAL ANALYSIS}

The reliability of the SpNQ scales was evaluated with internal consistency coefficients (Cronbach's alpha), 
which reflect the degree to which all items on a particular scale measure a single (uni-dimensional) concept. To combine several items with similar content, we relied on the technique of factor analysis (extraction of main components with eigenvalues $>1$ ), which examines the correlations among a set of variables in order to achieve a set of more general 'factors'. Factor analyses were repeated rotating different numbers of items (Varimax rotation with Kaiser Normalization) in order to arrive at a solution embodying both the simplest structure and the most coherent one.

Reliability and factor analyses, analyses of variance (ANOVA), correlation (Spearman rho) and stepwise regression analyses were performed with SPSS 15.0 for Windows (SPSS GmbH Software, Munich). We considered a level of $\mathrm{p}<0.05$ as statistically significant.

\section{RESULTS}

\section{Demographic Characteristics}

Among 210 participants, 75\% were women and 25\% men. Their mean age was $53.7 \pm 12.2$ years. The majority $(67 \%)$ had chronic pain conditions (i.e., fibromyalgia, bone associated pain syndromes [low back pain, arthrosis, arthritis etc.], migraine/headache, and other), 28\% had cancer and were a contrasting group of patients with fatal diseases, and $5 \%$ patients with other chronic diseases.

Most patients were married (61\%) or lived with a partner not married with $(12 \%), 12 \%$ lived alone (single), 10\% were divorced and 5\% widowed. Thirtyone $\%$ had a secondary education (Hauptschule), 28\% had a junior high school education (Realschule), 23\% a high school education (Gymnasium), and 18\% other.

A Christian affiliation was predominating (78\%), $8 \%$ had other religious affiliations, and $14 \%$ none.

Compared to patients with cancer, individuals with chronic pain conditions had significantly longer duration of disease, higher symptom scores, lower life satisfaction, and satisfaction with health situation and treatment efficacy (Table 1).

\section{RELIABILITY AND FACTOR ANALYSis}

From the primarily 24 item pool, item N3 (someone of our community (i.e. priest) who cares for you) had to be eliminated because of a poor corrected Item-Total correlation, while items N9 (listening to touching music), N16 (forgive someone) and N17 (be forgiven) were removed from the item pool because of a factor loading $<0.5$ and/or stronger side loadings. Item N24 (being complete and safe) would make up an independent 1item factor and thus was used as a marker item.

As shown in Table 2, the resulting 19-item construct had a good internal consistency (Cronbach's alpha $=.932)$. The item difficulty (1.20 [mean value] / 3) was .40; all values were in the acceptable range from .20 to .80 .

Primary factor analysis revealed a Kaiser-MayerOlkin value of .910 , which as a measure for the degree of common variance, indicates that the item-pool is suitable for a factorial validation. Exploratory factor analysis pointed to a 4-factor solution (all with initial eigenvalues $>1$ ), which would explain $67 \%$ of variance (Table 2):

- Religious Needs (6 items, alpha $=.903$ ) enrolling praying for and with others, and by themselves, participate at a religious ceremony, reading religious/ spiritual books, and turning to a higher presence.

- Need for Inner Peace (5 items, alpha $=.826$ ), enrolling patients' wish to dwell at places of quietness and pace, plunge into the beauty of nature, finding inner peace, but also talking with other about fears and worries, and devotion by others.

- Existentialistic Needs (Reflection/Meaning)(5 items, alpha $=.837)$ in terms of reflection and meaning in life and suffering, dissolve open aspects in life, talk about the possibility of a life after death.

- Actively Giving (3 items, alpha = .818) addresses the active and autonomous intention to solace someone, to give away something from yourself, and turning to others.

Item N12 (talking with someone about the possibility of life after death) from the Existentialistic Needs

Table 1. Health status of patients. Satisfaction scores $>50 \%$ indicate patients's satisfaction with the respective conditions, and scores $<50 \%$ their dissatisfaction.

\begin{tabular}{lcccccc}
\hline & & $\begin{array}{c}\text { Suration of } \\
\text { disease } \\
\text { (months) }\end{array}$ & $\begin{array}{c}\text { Symptom } \\
\text { score } \\
\text { (VAS) } \\
{[0-100]}\end{array}$ & $\begin{array}{c}\text { Life } \\
\text { Satisfaction } \\
\text { (BMLSS) } \\
{[0-100]}\end{array}$ & $\begin{array}{c}\text { Satisfaction } \\
\text { Health } \\
\text { situation } \\
\text { [score 0-6] }\end{array}$ & $\begin{array}{c}\text { Satisfaction } \\
\text { Treatment } \\
\text { efficacy } \\
{[\text { score 0-6] }}\end{array}$ \\
\hline Cancer & Mean & 52.7 & 39.9 & 74.4 & 3.7 & 4.6 \\
Chronic pain & SD & 58.9 & 25.6 & 17.3 & 1.7 & 1.4 \\
All patients & Mean & 124.9 & 69.2 & 57.4 & 2.1 & 3.4 \\
& SD & 102.5 & 15.2 & 21.3 & 1.4 & 1.4 \\
& Mean & 99.1 & 60.2 & 63.1 & 2.6 & 3.8 \\
& SD & 95.6 & 23.3 & 21.5 & 1.7 & 1.5 \\
\hline
\end{tabular}

\footnotetext{
* Results of patients with other chronic conditions ( $\mathrm{n}=10$ ) were not depicted
} 
Table 2. Reliability and factor analysis. Principal Component Analysis; Varimax Rotation with Kaiser Normalization (rotation converged in 6 Iterations). * marker items.

\begin{tabular}{|c|c|c|c|c|c|c|c|c|c|c|}
\hline & \multirow[t]{2}{*}{ Factors and Items } & \multirow{2}{*}{$\begin{array}{l}\text { Mean } \\
\text { value }\end{array}$} & \multirow[t]{2}{*}{ SD } & \multirow{2}{*}{$\begin{array}{l}\text { Difficulty } \\
\text { Index }\end{array}$} & \multirow{2}{*}{$\begin{array}{l}\text { corrected } \\
\text { Item-Total } \\
\text { correlation }\end{array}$} & \multirow{2}{*}{$\begin{array}{l}\text { Alpha if } \\
\text { Item } \\
\text { deleted }\end{array}$} & \multicolumn{4}{|c|}{ Factor loading } \\
\hline & & & & & & & I & II & III & IV \\
\hline & \multicolumn{10}{|l|}{ Religious needs (eigenvalue 8.6; alpha $=0.903$ ) } \\
\hline N18 & pray with someone & 0.65 & 0.94 & 0.22 & .603 & .929 & .813 & & & \\
\hline N20 & pray for yourself & 1.12 & 1.09 & 0.37 & .684 & .927 & .811 & & & \\
\hline N19 & someone prays for you & 0.85 & 1.04 & 0.28 & .673 & .927 & .801 & & & \\
\hline N21 & participate at a religious ceremony (i.e. service) & 0.90 & 1.02 & 0.30 & .677 & .927 & .769 & & & \\
\hline $\mathrm{N} 22$ & read religious / spiritual books & 0.82 & 1.03 & 0.27 & .633 & .928 & .720 & & .363 & \\
\hline \multirow[t]{2}{*}{$\mathrm{N} 23$} & turn to a higher presence (i.e. God. Angels ...) & 1.18 & 1.15 & 0.39 & .684 & .927 & .685 & & & \\
\hline & \multicolumn{10}{|c|}{ Need for Inner Peace (eigenvalue 1.9; apha $=.826$ ) } \\
\hline N7 & dwell at a place of quietness and peace & 1.66 & 1.07 & 0.55 & .622 & .928 & & .733 & .314 & \\
\hline $\mathrm{N} 2$ & talk with others about my fears and worries & 1.46 & 0.92 & 0.49 & .510 & .930 & & .703 & & \\
\hline N8 & find inner peace & 1.75 & 1.09 & 0.58 & .707 & .926 & & .649 & .392 & \\
\hline N6 & plunge into beauty of nature & 1.76 & 1.09 & 0.59 & .587 & .929 & & .640 & & \\
\hline \multirow[t]{2}{*}{ N1 } & higher devotion by others & 1.25 & 0.96 & 0.42 & .512 & .930 & & .603 & & .467 \\
\hline & \multicolumn{10}{|c|}{ Existentialistic needs (Reflection / Meaning) (eigenvalue 1.3; alpha $=.837$ ) } \\
\hline N4 & reflect your previous life & 1.12 & 0.93 & 0.37 & .527 & .930 & & .302 & .729 & \\
\hline \multicolumn{10}{|c|}{ meaning in life } & \\
\hline N5 & dissolve open aspects of your life & 1.22 & 1.01 & 0.41 & .591 & .929 & & .445 & .643 & \\
\hline N10 & find meaning in illness and/or suffering & 1.11 & 1.09 & 0.37 & .572 & .929 & & & .634 & .393 \\
\hline \multirow[t]{2}{*}{ N12 } & $\begin{array}{l}\text { talk with someone about the possibility of } \\
\text { life after death }\end{array}$ & 0.79 & 1.01 & 0.26 & .665 & .927 & .504 & & .627 & \\
\hline & Actively Giving (eigenvalue 1.1; alpha $=.818$ ) & & & & & & & & & \\
\hline N14 & give away something from yourself & 1.20 & 1.03 & 0.40 & .591 & .929 & & & & .766 \\
\hline N15 & solace someone & 1.42 & 0.97 & 0.40 & .587 & .929 & & & & .728 \\
\hline N13 & turn to someone in a loving attitude & 1.67 & 1.01 & 0.56 & .664 & .927 & & .447 & & .645 \\
\hline \multicolumn{2}{|c|}{$\mathrm{N} 24 *$ being complete and safe } & 1.92 & 1.14 & 0.47 & - & - & & & & \\
\hline \multicolumn{2}{|c|}{$\mathrm{N} 17 *$ be forgiven } & 1.04 & 1.06 & 0.56 & - & - & & & & \\
\hline
\end{tabular}

scale would load also on the scale Religious Needs (.50).

\section{IMPORTANCE OF SPIRITUAL NEEDS AND INFLUENCING VARIABLES}

As shown in Figure 1, Inner Peace and also Actively Giving were the needs with the highest relevance, particularly for patients with cancer, while Existentialistic Needs and also Religious Needs were of low importance for patients with chronic pain conditions, but of some importance for patients with cancer (Fig. 1).

To analyze the impact of covariates (and their interactions), i.e., age, educational level, family status and underlying disease, we performed univariate analyses (GLM univariate, between subject effects). Gender had no significant impact on the needs scales (data not shown). Several variables had a weak impact on the respective scales (Levenne's test of equality of error variance was significant in all cases, and thus the level of significance should be .01), i.e., age and family status had an influence on Religious Needs ( $\mathrm{F}=2.6$, df $10, \mathrm{p}=.008)$; educational level $(\mathrm{F}=3.6$, df 3 , $\mathrm{p}=.016)$ and age and educational level $(\mathrm{F}=2.2$, df 11, $\mathrm{p}=.019)$ had in trend an impact on Inner Peace; Ex- istentialistic Needs were significantly influenced by the underlying disease $(\mathrm{F}=2.2$, df $1, \mathrm{p}<.0001)$, by age,

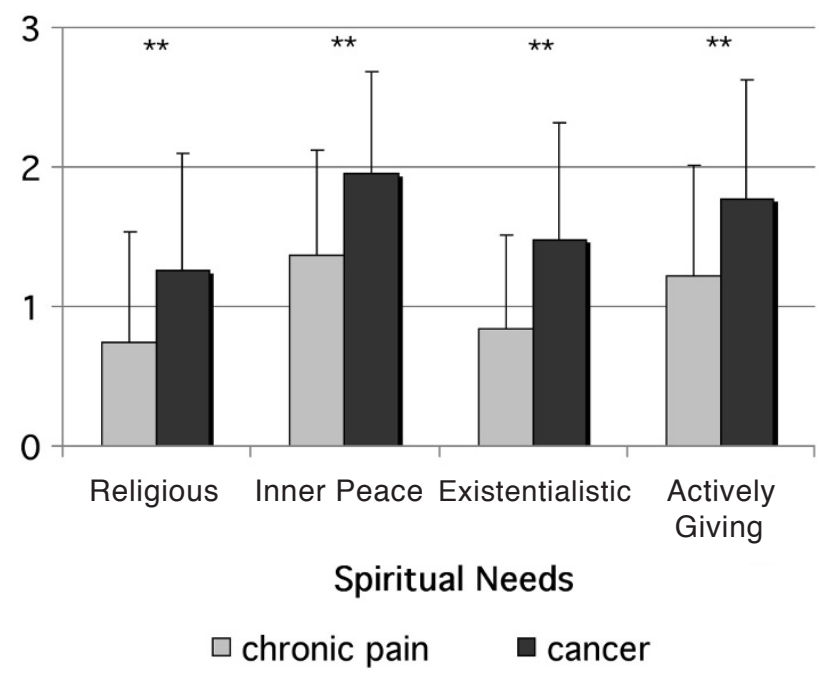

Fig. 1. Importance of Spiritual needs of patients with chronic pain diseases and cancer. Importance of spiritual needs range from 0 to 3 ( 0 - not important at all; 1 - somewhat important; 2 - very important; 3 - extremely important). ${ }^{* *} \mathrm{p}<0.001$ (ANOVA) 
Table 3. Correlation between Spiritual Needs, Life Satisfaction and symptom score of patients with chronic diseases. ${ }^{* *} \mathrm{p}<0.01$ (Spearman rho; 2-tailed).

\begin{tabular}{|c|c|c|c|c|}
\hline & Religious needs & Inner Peace & Existentialistic Needs & Actively Giving \\
\hline Religious needs & 1,000 &, $554 * *$ &, $625^{* *}$ &, $561 * *$ \\
\hline Inner Peace & & 1,000 &, $642 * *$ &, $590 * *$ \\
\hline Existentialistic needs & & & 1,000 &, $594 * *$ \\
\hline Actively Giving & & & & 1,000 \\
\hline Life Satisfaction Sum &, 070 &, 117 &, 054 &, 173 \\
\hline Family life &, 032 &, 049 &, 002 & ,085 \\
\hline Friendships &, 017 & ,132 & ,026 &, 174 \\
\hline Work &, 030 &,- 005 &,- 019 & ,082 \\
\hline Self & 129 & 147 &, 110 &, $189 * *$ \\
\hline Living area &, 072 & 118 & 011 &, 110 \\
\hline overall Live & ,138 & 142 &, 135 &, $195^{* *}$ \\
\hline Financial situation &,- 080 &,- 054 &,- 134 &, 037 \\
\hline Future prospects & ,105 &, 100 & ,091 & ,173 \\
\hline Satisfaction Health situation & 163 &, 157 & 128 &, 170 \\
\hline Satisfaction Treatment efficacy / efforts & ,175 &, $242^{* *}$ &, 171 &, $185^{* *}$ \\
\hline Symptom score (VAS) &,- 130 &,- 137 &,- 174 &,$- 292 * *$ \\
\hline
\end{tabular}

Table 4. Predictors of SpR needs (stepwise regression model).

\begin{tabular}{llllll}
\hline Dependent Variables & Predictors & $\mathbf{R}^{2}$ & Beta & T & Sign. \\
\hline Religious Needs & (Constant) & .104 & & .698 & .487 \\
& Cancer & & .262 & 3.282 & .001 \\
& Source (Sample) & & .184 & 2.306 & .023 \\
Need for Inner Peace & (Constant) & .197 & & 4.479 & .000 \\
& Cancer & & .393 & 5.048 & .000 \\
& Age & & -.186 & -2.389 & .018 \\
Existentialistic Needs (Sample) & & .161 & 2.108 & .037 \\
& Source (Constant) & .193 & & & \\
& Cancer & & .373 & 4.748 & .026 \\
& Source (Sample) & & .223 & 2.938 & .000 \\
& Age & & -.167 & -2.153 & .033 \\
Actively Giving & (Constant) & .257 & & 2.485 & .014 \\
& Cancer & & .2 .98 & 3.766 & .000 \\
& Source (sample) & & .283 & 3.854 & .000 \\
& Age & & -.245 & -3.254 & .001 \\
& Life Satisfaction & & .198 & 2.505 & .013 \\
\hline
\end{tabular}

* Only the strongest prediction model was presented (all variables not mentioned in the table were excluded from the respective model)

educational level and disease $(\mathrm{F}=2.8$, df $6, \mathrm{p}=$ $.013)$, and by age, family status and educational level $(\mathrm{F}=2.3$, df 6, $\mathrm{p}=.038) ;$ Actively Giving was in trend influenced by age, educational level and disease ( $\mathrm{F}=$ 2.3 , df $6, \mathrm{p}=.039)$, and age, family status and educational level $(\mathrm{F}=2.3$, df $6, \mathrm{p}=.043)$.

\section{Correlation ANALYsis}

To make statements about the conceptual relationships of spiritual needs with live satisfaction (in terms of divergent validity, because we assume that low life satisfaction in the respective dimensions might be associated with higher needs and vice versa), satisfaction with health status and symptom scores, we performed correlation analyses (Table 3 ). There were just some weak associations between Actively Giving and life satisfaction $(\mathrm{r}=.17 ; \mathrm{p}=.012)$, and negatively with the symptom score $(\mathrm{r}=-.29 ; \mathrm{p}<.0001)$; Need for Inner Peace was weakly associated with satisfaction with treatment efficacy $(r=.24 ; \mathrm{p}<.0001)$.

\section{Predictors of Spiritual NeEds}

To determine putative predictors of spiritual needs, we performed stepwise regression analyses enrolling variables such as underlying disease, duration of disease, source (enrolling centre), life satisfaction, satisfaction 
with treatment effectiveness, intensity of symptoms, and age. As shown in Table 4, cancer as underlying disease and the source were the best predictors for all SpNQ scales, albeit with weak predictive power $\left(\mathrm{R}^{2}\right.$ $<.30)$. For both Inner Peace and Existentialistic Needs the predictors disease and source were negatively modulated by age. Actively Giving was predicted by disease, source and age, too, and positively modulated by life satisfaction.

\section{DISCUSSION}

Our intention was to design an instrument which addresses spiritual, psychosocial and existential needs of patients dealing with chronic diseases. Previous research has shown that even individuals which would not regard themselves as religious or spiritual (R-S-) nevertheless do value aspects of spirituality in their life, i.e., gratitude and awe; compassion and generosity; conscious interactions (with others, self, and environment); and insight and wisdom [33]. These R-Sindividuals are engaged in humanistic and social issues [34], and thus value secular humanism much higher than institutional religiosity. To account for the fact that among Europe's patients with chronic diseases several do not regard themselves as religious (despite of an alleged Christian denomination) $[12,14,17,36$, 38], but nevertheless may have spiritual, psychosocial and existential needs which may not be recognized in a clinical context, the attained structure of the questionnaire seems appropriate. We differentiated (1) Religious Needs including both private and public domains of religiosity (which thus is a domain of Spiritual Connecting), (2) Need for Inner Peace in the context of distinct peaceful places and being one with nature and with others, i.e., talking with others about fears and worries, and devotion by others (which thus is a domain of Connecting and Becoming), (3) Existentialistic Needs with a focus on reflection and meaning in life and suffering, and also life after death (which thus is a domain of both Meaning and Becoming), and (4) Actively giving in terms of solace, turning to others etc. (which thus is a domain of Connecting). This later aspect is of outstanding importance because it can be interpreted as patients' intention to leave the role model of a 'passive sufferer' to become an active, self-actualizing giving individual. Preliminary data of an ongoing study enrolling patients with cancer confirm both the 4-factorial structure of the SpRNQ and construct validity (Höcker et al., in preparation).

Compared to the five dimensions of the Spiritual Needs Scale (SNS) of Yong et al. [32] (Table 5), we have similar dimensions, albeit with different weightings, but lack the scale 'acceptance of dying'; this topic was addressed with the single items N12 (talk with someone about the possibility of life after death) and N5 (dissolve open aspects of your life) of the Existentialistic Needs scale. Due to strong side loadings, the items dealing with the topic of Forgiveness were eliminated from the item pool; nevertheless, item N17 (to be forgiven) can be used as a marker item.

With respect to the topics extracted from qualitative investigations of the spiritual perspectives of adults at
Table 5. Comparison of spiritual need dimensions.

\begin{tabular}{ll}
\hline $\begin{array}{l}\text { Spiritual Need Scale } \\
\text { (SNS) (Yong et al. [32]) }\end{array}$ & $\begin{array}{l}\text { Spiritual Needs Questionnaire } \\
\text { (SpNQ) (Büssing et al.) }\end{array}$ \\
\hline o relationship with God & o Religious Needs \\
o meaning and purpose & $\begin{array}{l}\text { o Existentialistic Needs } \\
\text { (Reflection / Meaning) }\end{array}$ \\
o acceptance of dying & $-\quad$ Single items N12 and N5 \\
$\begin{array}{l}\text { o hope and peace } \\
\text { o love and connection }\end{array}$ & $\begin{array}{l}\text { o Need for Inner Peace } \\
\text { o Actively Giving }\end{array}$ \\
\hline
\end{tabular}

the end of life [39], our scales fit to the motifs spiritual work (self-exploration, search for balance), and spiritual well-being (connection, self-actualization, consonance), while spiritual despair (alienation, loss of self, dissonance) was not in line with our intentions.

The preliminary results of this study indicate that finding Inner Peace and Actively Giving were of outstanding relevance for the investigated cohorts, while particularly the conventional Religious Needs were of minor importance. This is in contrast to findings of others [19] which demonstrated that religion was important to most advanced cancer patients. However, these strong religious needs were particularly stated by African Americans and Hispanics [19], while our study enrolled Caucasians. Moreover, Balboni et al. found that patients' spiritual needs was associated with improved quality of life [19]. In our study, we analyzed life satisfaction rather than functional quality of life, because even patients with impaired perception of health status can have high satisfaction with various dimensions of life concerns. While it is true that patients with chronic disease may experience decreased quality of life and life satisfaction, it is not necessarily true for all individuals. Specifically, there is increasing evidence that cancer patients not only experience traumatic stress, but in several cases also personal growth (reviewed in [40]). Also in HIV infected individuals one may observe an increase of religiousness/spirituality which may predict slower disease progression [41]. In a recent study we have confirmed that several dimensions of life satisfaction of patients with chronic pain diseases can be high despite of the experience of chronic pain [37]. However, in the patients analysed herein, life satisfaction was not significantly associated with the spirituals needs, indicating that both concepts are different.

The exclusive focus on both patients with non-fatal and not primarily life-threatening diseases (i.e., chronic pain conditions), and cancer, which served as a contrasting group of patients with a fatal disease, was the intention of the study, because most studies on this important topic address mainly terminally-ill patients. A limitation of our study could be that we have enrolled not only cancer patients from an out-patient clinic, but also attendants engaged in a cancer support group. One may assume that the later sample comprises more active patients (and thus they were attending a cancer support group conference) than the conventional out-patients; as a consequence, the needs of this distinct cohort might be higher than in a normal pop- 
ulation. In fact, particularly with respect to the scale Actively Giving the conference attending patients had higher scores than the out-patients $(\mathrm{F}(1,55)=6.0 ; \mathrm{p}=$ $.004)$. Thus, further studies which are currently under way will enrol patients with more diverse diseases and different stages of disease, and address other independent (external) criteria. Another important issue which has to be addressed in a longitudinal study is a putative response shift during the treatment.

In conclusion, we were able to confirm the SpNQ designed to measure spiritual needs of patients with long-lasting courses of disease. Particularly in the context of health care research in Europe it is important to have a scale which assesses patients' spiritual needs in a much more open context of spirituality. The preliminary results indicate that these spiritual needs are conceptually different from life satisfaction, and share just some weak associations with patients' satisfaction with their treatment efficacy or symptom score. These needs can be regarded as the patients' longing for spiritual well-being. However, methods how health care professionals may meet the patients' spiritual needs remain to be explored; also the assessment of the usefulness of such interventions in the context of health care research.

\section{REFERENCES}

1. Büssing A, Ostermann T, Matthiessen PF. Adaptive coping and spirituality as a resource in cancer patients. Breast Care. 20072): 195-202.

2. Koenig HG, Larson DB, Larson SS. Religion and coping with serious medical illness. Ann Pharmacother. 2001; 35(3): 352-9.

3. Bussing A, Ostermann T, Koenig HG. Relevance of religion and spirituality in German patients with chronic diseases. Int J Psychiatry Med. 2007; 37(1): 39-57.

4. Koenig HG, Pargament KI, Nielsen J. Religious coping and health status in medically ill hospitalized older adults. J Nerv Ment Dis. 1998; 186(9): 513-21.

5. Koenig HG. Spirituality and depression: a look at the evidence. South Med J. 2007; 100(7): 737-9.

6. McClain CS, Rosenfeld B, Breitbart W. Effect of spiritual well-being on end-of-life despair in terminally-ill cancer patients. Lancet. 2003; 361(9369): 1603-7.

7. Sloan RP, Bagiella E. Claims about religious involvement and health outcomes. Ann Behav Med. 2002; 24(1): 1421.

8. Wachholtz AB, Pearce MJ. Does spirituality as a coping mechanism help or hinder coping with chronic pain? Curr Pain Headache Rep. 2009; 13(2): 127-32.

9. Koenig HG. Research on religion, spirituality, and mental health: a review. Can J Psychiatry. 2009; 54(5): 283-91.

10. McCullough ME, Willoughby BL. Religion, self-regulation, and self-control: Associations, explanations, and implications. Psychol Bull. 2009; 135(1): 69-93.

11. Chida Y, Steptoe A, Powell LH. Religiosity/spirituality and mortality. A systematic quantitative review. Psychother Psychosom. 2009; 78(2): 81-90.

12. Thune-Boyle IC, Stygall JA, Keshtgar MR, Newman SP. Do religious/spiritual coping strategies affect illness adjustment in patients with cancer? A systematic review of the literature. Soc Sci Med. 2006; 63(1): 151-64.

13. Büssing A, Ostermann T, Matthiessen PF. Role of Religion and Spirituality in Medical patients in Germany. Journal of Religion and Health. 2005; 44(3): 321-40.

14. Büssing A, Michalsen A, Balzat HJ, Grunther RA, Ostermann T, Neugebauer EA et al. Are spirituality and reli- giosity resources for patients with chronic pain conditions? Pain Med. 2009; 10(2): 327-39.

15. Wachholtz AB, Pearce MJ. Does spirituality as a coping mechanism help or hinder coping with chronic pain? Curr Pain Headache Rep. 2009; 13(2): 127-32.

16. Büssing A, Ostermann T, Matthiessen PF. Search for meaningful support and the meaning of illness in German cancer patients. Anticancer Res. 2005; 25(2B): 144955.

17. Büssing A, Ostermann T, Koenig HG. Relevance of religion and spirituality in German patients with chronic diseases. Int J Psychiatry Med. 2007; 37(1): 39-57.

18. Thune-Boyle IC, Stygall JA, Keshtgar MR, Newman SP. Do religious/spiritual coping strategies affect illness adjustment in patients with cancer? A systematic review of the literature. Soc Sci Med. 2006; 63(1): 151-64.

19. Balboni TA, Vanderwerker LC, Block SD, Paulk ME, Lathan CS, Peteet JR et al. Religiousness and spiritual support among advanced cancer patients and associations with end-of-life treatment preferences and quality of life. J Clin Oncol. 2007; 25(5): 555-60.

20. Murray SA, Kendall M, Boyd K, Worth A, Benton TF. Exploring the spiritual needs of people dying of lung cancer or heart failure: a prospective qualitative interview study of patients and their carers. Palliat Med. 2004; 18(1): 39-45.

21. Hermann C. Development and testing of the spiritual needs inventory for patients near the end of life. Oncol Nurs Forum. 2006; 33(4): 737-44.

22. Hermann CP. The degree to which spiritual needs of patients near the end of life are met. Oncol Nurs Forum. 2007; 34(1): 70-8.

23. Williams AL. Perspectives on spirituality at the end of life: a meta-summary. Palliat Support Care. 2006; 4(4): 407-17.

24. Grant E, Murray SA, Kendall M, Boyd K, Tilley S, Ryan D. Spiritual issues and needs: perspectives from patients with advanced cancer and nonmalignant disease. A qualitative study. Palliat Support Care. 2004; 2(4): 371-8.

25. Hampton DM, Hollis DE, Lloyd DA, Taylor J, McMillan SC. Spiritual needs of persons with advanced cancer. Am J Hosp Palliat Care. 2007; 24(1): 42-8.

26. Shih FJ, Lin HR, Gau ML, Chen CH, Hsiao SM, Shih SN et al. Spiritual needs of Taiwan's older patients with terminal cancer. Oncol Nurs Forum. 2009; 36(1): E31E38.

27. Raoul M, Rougeron C. [Spiritual needs of end of life home care patients: a qualitative study with 13 patients]. J Int Bioethique. 2007; 18(3): 63-83, 117.

28. Daaleman TP, Usher BM, Williams SW, Rawlings J, Hanson LC. An exploratory study of spiritual care at the end of life. Ann Fam Med. 2008; 6(5): 406-11.

29. Grant E, Murray SA, Kendall M, Boyd K, Tilley S, Ryan D. Spiritual issues and needs: perspectives from patients with advanced cancer and nonmalignant disease. A qualitative study. Palliat Support Care. 2004; 2(4): 371-8.

30. Williams AL. Perspectives on spirituality at the end of life: a meta-summary. Palliat Support Care. 2006; 4(4): 407-17.

31. Moadel A, Morgan C, Fatone A, Grennan J, Carter J, Laruffa $G$ et al. Seeking meaning and hope: self-reported spiritual and existential needs among an ethnically-diverse cancer patient population. Psychooncology. 1999; 8(5): 378-85.

32. Yong J, Kim J, Han SS, Puchalski CM. Development and validation of a scale assessing spiritual needs for Korean patients with cancer. J Palliat Care. 2008; 24(4): 240-6.

33. Büssing A, Ostermann T, Matthiessen PF. Distinct expressions of vital spirituality. The ASP questionnaire as an explorative research tool. Journal of Religion and Health. 2007; 46(2): 267-86. 
34. Büssing A, Matthiessen PF, Ostermann T. Engagement of patients in religious and spiritual practices: confirmatory results with the SpREUK-P 1.1 questionnaire as a tool of quality of life research. Health Qual Life Outcomes. 2005; 30: 53.

35. Büssing A, Ostermann T, Matthiessen PF. Role of religion and spirituality in medical patients: confirmatory results with the SpREUK questionnaire. Health Qual Life Outcomes. 2005; 30: 10 .

36. Büssing A, Fischer J, Ostermann T, Matthiesen P.F. Reliance on God's help, depression and fatigue in female cancer patients. Int J Psychiatry Med. 2008; 38(3): 357-72.

37. Büssing A, Fischer J, Haller A, Ostermann T, Matthiessen PF. Validation of the Brief Multidimensional Life Satisfaction Scale in patients with chronic diseases. Eur J Med Res. 2009; 14(4): 171-7.

38. Büssing A, Abu-Hassan WM, Matthiessen PF, Ostermann T. Spirituality, religiosity, and dealing with illness in Arabic and German patients. Saudi Med J. 2007; 28(6): 933-42.

39. Williams AL. Perspectives on spirituality at the end of life: a meta-summary. Palliat Support Care. 2006; 4(4): 407-17.
40. Jim HS, Jacobsen PB. Posttraumatic stress and posttraumatic growth in cancer survivorship: a review. Cancer J. 2008; 14(6): 414-9.

41. Ironson G, Stuetzle R, Fletcher MA. An increase in religiousness/spirituality occurs after HIV diagnosis and predicts slower disease progression over 4 years in people with HIV. J Gen Intern Med. 2006; 21 Suppl 50: S62S68.

Received: November 10, 2009 / Accepted: May 14, 2010

Address for correspondence:

Prof. Dr. med. Arndt Büssing

Center for Integrative Medicine

Faculty of Medicine

University of Witten/Herdecke

Gerhard-Kienle-Weg 4

58313 Herdecke

Germany

Phone: +49-2330-623246

Email: Arndt.Buessing@uni-wh.de 